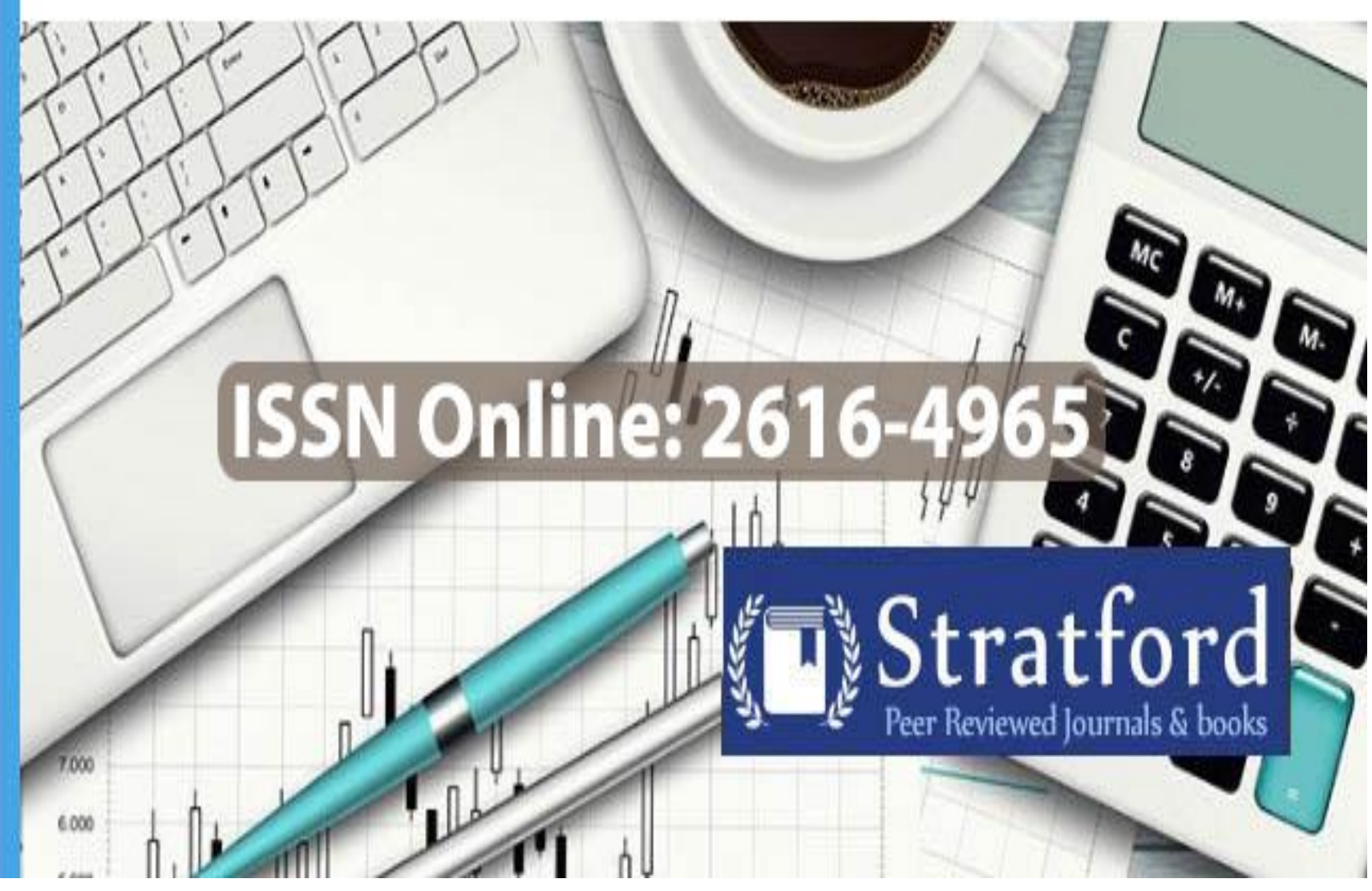

An Exploratory Study on the Role of Feasibility Study on Sustainability of Business in Kenya: A Case of Supermarkets in Nairobi County

Paul Kilote Jumah, Dr. Thomas Githui \& Martin Kweyu ISSN: 2616-4965 


\title{
An Exploratory Study on the Role of Feasibility Study on Sustainability of Business in Kenya: A Case of Supermarkets in Nairobi County
}

\author{
Paul Kilote Jumah, Dr. Thomas Githui \& Martin Kweyu \\ Postgraduate Student, School of Business, Catholic University of Eastern Africa \\ Lecturer, School of Business, Catholic University of Eastern Africa \\ Lecturer, School of Business, Catholic University of Eastern Africa \\ Email of corresponding author: pkilotte02@yahoo.com
}

How to cite this article: Jumah P. K, Githui T. \& Kweyu M (2022). An Exploratory Study on the Role of Feasibility Study on Sustainability of Business in Kenya: A Case of Supermarkets in Nairobi County. Journal of Finance and Accounting. Vol 6(1) pp. 57-70. https://doi.org/10.53819/81018102t2040

\section{Abstract}

Organizational strategic feasibility studies are critical in mitigating uncertainty in the business environment and enhancing growth and performance. This study sought to ascertain the role of feasibility studies in the sustainability of supermarkets in Nairobi County, Kenya. The study's specific objectives were to determine the impact of technical feasibility, economic feasibility, operational feasibility, and legal feasibility on the sustainability of supermarkets in Nairobi County, Kenya. A descriptive research design was used for the study. The study's target population was seven major supermarkets: Naivas, QuickMart, Cleanshelf, The Game Store, Chandarana, Eastmatt, and Carrefour. A questionnaire was used to collect primary data. Findings indicated that technical feasibility is positively and significantly related to the business sustainability of supermarkets in Nairobi County. The findings also revealed that economic feasibility is positively and significantly related to the business sustainability of supermarkets in Nairobi County. The findings revealed a positive and significant relationship between operational feasibility and business sustainability of supermarkets in Nairobi County. Finally, the findings revealed that the legal feasibility and business sustainability of Nairobi County supermarkets are positively and significantly related. The study concluded that technical feasibility, economic feasibility, operational feasibility, and legal feasibility all have a positive impact on supermarket business sustainability. The study recommends that supermarkets should become acquainted with the technical technology that is available on the market and evaluate those that are appropriate for their needs. Managers of Nairobi County supermarkets increase the level of internal and external benchmarking in their supermarkets for economic benefit assessments.

Keywords: Technical Feasibility, Economic Feasibility, Operational Feasibility, Legal Feasibility, Sustainability\& Supermarkets. 


\subsection{Introduction}

Organizational strategic feasibility studies are critical in mitigating uncertainty in the business environment and enhancing growth and performance. According to Maseko (2017), feasibility studies are an increasingly popular strategy that attempts to evaluate and manage all of the firm's uncertainties and risks (Florio \& Leoni, 2017). Due to retail and extension setbacks, retail businesses now operate in a difficult decision-making environment that necessitates a clear feasibility assessment. Feasibility studies are regarded as a critical factor in determining a company's competitiveness. It enables a company to devise a one-of-a-kind strategy for mitigating potential losses and opening the door to new opportunities (Martin \& Kinoti, 2017).

Supermarkets are a significant economic driver in Kenya's retail industry. The retail sector accounts for a sizable portion of Kenya's Gross Domestic Product (GDP). Additionally, retail is one of the six priority industries and is predicted to account for roughly half of all formal employment. Indeed, the sector's potential aligns perfectly with Vision 2030's economic pillar, which aspires to improve the well-being of all Kenyans by achieving a 10\% GDP growth rate. Kenya's retail market is the continent's second most developed, after only South Africa, and the continent's fastest growing sector, according to an Oxford Business Group research (Nzomo, 2017; Kanyora, 2019; Demmler, Ecker \& Qaim, 2018). Kenya's retail sector structure has mirrored that of major European and Asian economies. Muchiri (2019) defines retail sectors as dry foodstuffs (grains and cereals, packaged meals, toiletries, and home products), electronics, specific types of men's clothes, and shopping malls, citing Nairobi's Two Rivers Mall as an example. Dry grocery is particularly appealing due to the proliferation of brands and products that have aided in the improvement of retail margins on two levels: first, because they are packaged goods, suppliers must match retailers' better terms to obtain shelf space; and second, they emulate what upmarket supermarkets such as Tuskys in Nairobi's central business district do, such as attracting customers with frozen foods and offering a superior selection of goods. They can also provide discounts as a result of their larger margin spread.

Naivas, QuickMart, Cleanshelf, the Game Store, Chandarana, Eastmatt and Carrefour, Powerstar and Kassmart, and Mathais are among Kenya's major supermarkets. These large supermarkets have high market share with branches. They operate in an environment that is potentially vulnerable to competitive. As a result of the market's stifling competition, supermarket chains in Kenya are undergoing massive transformations as well as improvements. Client preference and choice, globalization of markets, government plans and treatments, and innovations, to name a few, have all resulted in radical changes in the retail industry (Martin \& Kinoti, 2017). The economic environment and other business environment changes have exposed several entities to collapse, near-collapse, and even receivership. Businesses, including Nakumatt, Choppies, and Uchumi supermarkets, are experiencing financial and operational difficulties. However, in the retail sector, major retail chain stores and supermarkets have struggled to stay afloat (Kang'ethe, Kiboi, \& Mathenge, 2019). The large supermarkets in Nairobi County were used in this study to determine the impact of feasibility assessment on business sustainability.

\subsection{Statement of the Problem}

A majority of supermarkets fail because they do not conduct a feasibility study prior to investing in business expansion. According to a survey conducted by the Retail Traders Association of Kenya (2020), the majority of respondents (37\%) were supermarkets, and $32.4 \%$ of retailers have plans to open new branches. Because the Kenyan supermarket retail sector operates in an 
environment that is potentially vulnerable to competitive actions, this has resulted in accumulated debts and the closure of supermarkets. The fall of dominant players in the sector, such as Nakumatt, Uchumi, Choppies, and Tuskys, demonstrates this. Tuskys owned and operated 60 supermarkets in Kenya and Uganda by 2018, while Nakumatt had 66 branches in East Africa. According to the Kenyan Competition Authority (2020), after analyzing the debt portfolios of 25 major retailers, four were in debt distress, but three were working to get back on track. Three of the four retailers presented payment plans and have been steadily reducing their debt portfolio.

Many retail companies are adopting comprehensive and integrated approaches due to the scope, complexity, and interdependence of emerging risks (Ndigwa \& Moronge, 2019). As a result, feasibility studies are required in retail organizations that face intelligent competition that can affect the organization's desired outcomes. Because of the volatile business environment, supermarkets should consider undertaking feasibility on their plans. As a result, the purpose of this research was to determine the role of feasibility studies in the business sustainability of supermarkets in Nairobi County, Kenya.

\subsection{Objectives of the Study}

The main objective of the study was to determine the role of feasibility study on business sustainability of supermarkets in Nairobi County, Kenya.

The study was guided by the following specific objectives:

i. To determine the influence of technical feasibility on business sustainability of supermarkets in Nairobi County, Kenya.

ii. To explore the influence of economic feasibility on business sustainability of supermarkets in Nairobi County, Kenya.

iii. To determine the influence of operational feasibility on business sustainability of supermarkets in Nairobi County, Kenya.

iv. To evaluate the influence of legal feasibility on business sustainability of supermarkets in Nairobi County, Kenya.

\subsection{Research Questions}

The study was guided by the following research questions;

i. What is the effect of technical feasibility on business sustainability of supermarkets in Nairobi County, Kenya?

ii. What is the effect of economic feasibility on business sustainability of supermarkets in Nairobi County, Kenya?

iii. What is the effect of operational feasibility on business sustainability of supermarkets in Nairobi County, Kenya?

iv. What is the effect of legal feasibility on business sustainability of supermarkets in Nairobi County, Kenya? 


\subsection{Literature Review}

\subsection{Theoretical Framework}

To explain the relationship between the study variables, two theories were used. The Resource Based View (RBV) Theory and the Diffusion of Innovation Theory were used to guide this research. In 1991, Barney proposed the Resource Based View theory. According to RBV, it is far easier to capitalize on new opportunities by leveraging existing resources and competencies, rather than learning new skills, traits, or functions for each opportunity. The RBV model's main focus is on these resources, with supporters arguing that they should be prioritized in organizational strategy development. The theory's central premise is that, rather than looking to the competitive business environment for a niche in the market or an advantage over competition and threats, the organization should instead look within at the resources and potential it already has.

Rogers (1962) developed the Innovation Theory. Diffusion of Innovation Theory began in correspondence to explain how a thought or item picks up energy and diffuses (or spreads) through an explicit populace or social framework after some time. Individuals, as a major component of a social framew ork, adopt another thought, behavior, or service/product as a result of this dispersion (Ma, Lee \& Goh, 2014). This is especially relevant in supermarkets, where there are strong incentives to develop differentiating new services that may provide them with a competitive advantage. The theory informs the study of technology's interaction, determining the key feasibility aspects of operational feasibility, technical feasibility, economic feasibility, and legal feasibility. The service innovation strategy is distinguished by the interaction of technological and human systems. Sustainability must clearly align their ideas in order to be business-sustainable.

\subsection{Conceptual Framework}

The conceptual framework for the study depicts the impact of the feasibility study on the sustainability of supermarkets. Supermarket business sustainability is the dependent variable, while the independent variables are operational feasibility, technical feasibility, economic feasibility, and legal feasibility. The framework is shown in Figure 1. 


\section{Technical Feasibility}

- Present scenario

- New development

- Competing technology

- Labor requirements

\section{Economic Feasibility}

- Cost benefit analysis

- Financial capability

- Profitability

\section{Operational Feasibility}

- Controls

- Operations

- Service provision

\section{Legal Feasibility}

- Contracts

- Liabilities

- Ethical practices

\section{Figure 1.1: Conceptual Framework}

\subsection{Research Methodology}

A descriptive research design was used. According to Cooper and Schindler (2016), in descriptive research, data is collected from members of a population and the researcher obtains descriptive existing phenomena by asking individuals about their perceptions, attitudes, behavior, or values. This study's target population included seven major supermarkets in Nairobi County, Kenya: Naivas, QuickMart, Cleanshelf, The Game Store, Chandarana, Eastmatt, and Carrefour. Top managers, middle managers and supervisors of the selected supermarkets were considered for the research because of their positioning to respond effectively in this study. From these supermarkets, the respondents were sampled from the various departments to ensure representation of the results. The target population is as shown in Table 1. 
Table 1: Target Population

\begin{tabular}{lcccc}
\hline Supermarket & Senior Management & Middle management & Supervisors & Total \\
\hline Naivas & 6 & 8 & 14 & 28 \\
Quickmart & 3 & 6 & 8 & 17 \\
Cleanshelf & 3 & 6 & 8 & 17 \\
Game Store & 4 & 8 & 12 & 24 \\
Chandarana & 5 & 8 & 9 & 22 \\
Eastmatt & 2 & 4 & 8 & 14 \\
Carrefour & 5 & 8 & 12 & 25 \\
Total & 28 & 48 & 71 & 147 \\
\hline
\end{tabular}

As a result, the population target was 147 top, middle, and supervisors working in Nairobi County's seven major supermarkets and their branches. For the senior management, middle management, and supervisors, the study used a census approach sampling. Since the target population was small, the entire population of 147 top, middle, and supervisors was used in the study to make the sample more representative. As a result, the sample size was 147 people. A questionnaire was used to collect primary data. To summarize, organize, interpret, and present the primary data collected for this study, descriptive and inferential statistics were used. The descriptive statistical techniques of frequency tables, percentages, pie charts, and bar charts were used to summarize and present background information about the study's respondents in an informative manner. The inferential statistical tool Spearman rank correlation coefficient, together with appropriate hypothesis statements for the specific research objectives, was used to measure the extent of association between the independent and dependent variables of the study. Further, regression analysis was employed to ascertain the relationship between the independent and dependent variables.

\subsection{Results and Findings}

The response rate was examined in order to determine the representativeness of the sample size. A total of 147 copies of the questionnaire were distributed as part of the study of which, 138 were filled in and returned. Table 4.2 displays the response rate results. Out of the 147 respondents, 138 respondents completed the questionnaires, resulting to a $93.8 \%$ response rate.

\subsection{Correlation Analysis}

The Spearman rank correlation analysis was used to determine the strength of the link between the study's independent and dependent variables. The feasibility of supermarkets in Nairobi County, Kenya was determined by their technological feasibility, economic feasibility, operational feasibility, legal feasibility, and business sustainability. Table 2 contains the Spearman rank correlation matrix. 
Stratford Peer Reviewed Journals and Book Publishing

Journal of Finance and Accounting

Volume 6||Issue 1||Page 57-70 ||January||2022|

Email: info@stratfordjournals.org ISSN: 2616-4965

Table 2: Spearman Rank Correlation Matrix

\begin{tabular}{|c|c|c|c|c|c|c|}
\hline & & $\begin{array}{l}\text { Sustain- } \\
\text { ability }\end{array}$ & $\begin{array}{l}\text { Technical } \\
\text { Feasibility }\end{array}$ & $\begin{array}{l}\text { Economic } \\
\text { Feasibility }\end{array}$ & $\begin{array}{c}\text { Operational } \\
\text { Feasibility }\end{array}$ & $\begin{array}{c}\text { Legal } \\
\text { Feasibility }\end{array}$ \\
\hline \multirow{9}{*}{$\begin{array}{l}\text { Spearman's } \\
\text { rho }\end{array}$} & Sustainability & 1.000 & & & & \\
\hline & Technical & $.743 * *$ & 1.000 & & & \\
\hline & Feasibility & 0.000 & . & & & \\
\hline & Economic & $.759 * *$ & $.645^{* *}$ & 1.000 & & \\
\hline & Feasibility & 0.000 & 0.000 & . & & \\
\hline & Operational & $.742 *$ & $.639 * *$ & $.647 * *$ & 1.000 & \\
\hline & Feasibility & 0.000 & 0.000 & 0.000 & & \\
\hline & Legal & $.778 * *$ & $.642 * *$ & $.647 * *$ & $.693 * *$ & 1.000 \\
\hline & Feasibility & 0.000 & 0.000 & 0.000 & 0.000 & \\
\hline
\end{tabular}

Technical feasibility $\left(\mathrm{r}=0.743^{* *}, \mathrm{p}=0.000\right)$ was found to be positively and significantly associated with supermarket business sustainability in Nairobi County. This implies that the level of association between Technical feasibility and supermarket business sustainability was up to 74.3\% . Additionally, economic feasibility $\left(\mathrm{r}=0.759^{* *}, \mathrm{p}=0.000\right)$ was found to be positively and significantly associated with supermarket business sustainability in Nairobi County. This implies that the level of association between economic feasibility and supermarket business sustainability was up to $75.9 \%$. The results indicated a favorable and substantial relationship between operational feasibility $\left(\mathrm{r}=0.742^{*}, \mathrm{p}=0.000\right)$ and business sustainability of supermarkets in Nairobi County. This implies that the level of association between operational feasibility and supermarket business sustainability was up to $74.2 \%$. Finally, the results indicated a favorable and substantial relationship between legal feasibility $\left(\mathrm{r}=0.778^{* *}, \mathrm{p}=0.000\right)$ and business sustainability of supermarkets in Nairobi County. This implies that the level of association between legal feasibility and supermarket business sustainability was up to $77.8 \%$. This means that an improvement in the technological feasibility, economic feasibility, operational feasibility, and legal feasibility of supermarkets in Nairobi County would result in an increase in their business sustainability.

\subsection{Diagnostic Tests}

The pre- and post-estimation tests were undertaken prior to running a regression model. The normalcy, multicollinearity, heteroscedasticity, and linearity tests are used as pre-estimation tests in this scenario.

The Shapiro-Wilk test was employed to determine the normality of the variables because it has the highest power of all normality tests. The hypothesis was tested at a critical value of 0.05 , with the criterion being that one should reject $\mathrm{H}_{0}$ if the probability $(\mathrm{P})$ value is less than 0.05 , or else one should not reject. The dependent variable should have a normally distributed distribution since the study will be evaluated using a multiple regression model that requires normality (Quataroli \& Julia, 2012). The results for normality are as shown in Table 3. 
Table 3: Normality Outputs

\begin{tabular}{llll}
\hline Variables & $\begin{array}{l}\text { Shapiro-Wilk } \\
\text { Statistic }\end{array}$ & df & Sig. \\
\hline Technical Feasibility & 0.949 & 138 & 0.267 \\
Economic Feasibility & 0.949 & 138 & 0.128 \\
Operational Feasibility & 0.933 & 138 & 0.355 \\
Legal Feasibility & 0.955 & 138 & 0.135 \\
Sustainability & 0.934 & 138 & 0.327 \\
\hline
\end{tabular}

The results indicate that, when the Shapiro-Wilk normality test is used, the data are normal because the p-values for all variables are more than 0.05, and hence the hypothesis is not rejected. As a result, the distribution of the variables: technical feasibility, economic feasibility, operational feasibility, legal feasibility, and sustainability was normal, allowing for additional study.

The multicollinearity test was used to measure the degree of correlation between two or more predictor (independent) variables in the regression model. To test for multicollinearity, the variance inflation factor (VIF) was used, and a VIF of less than 10 suggested acceptable boundaries. When the VIF value of exploratory variables exceeds 10, they are considered extremely collinear.

Table 4: Multicollinearity Test Using Tolerance and VIF

\begin{tabular}{lcc}
\hline (Constant) & $\begin{array}{c}\text { Collinearity Statistics } \\
\text { Tolerance }\end{array}$ & VIF \\
\hline Technical Feasibility & 0.340 & 2.944 \\
Economic Feasibility & 0.292 & 3.429 \\
Operational Feasibility & 0.305 & 3.281 \\
Legal Feasibility & 0.407 & 2.459 \\
\hline
\end{tabular}

The above findings, indicate that all the variables had tolerance values $>0.2$ and VIF values $<10$. Thus according to Myres (2015), where VIF $\geq 10$ indicate presence of multicollinearity, there was no multicollinearity among the independent variables.

Heteroscedasticity occurs when a variable's variability is unequal throughout the range of values of another variable that predicts it. Without taking heteroscedasticity into account, a regression model would produce unbiased parameter estimates. The Breusch-Pagan/Godfrey test was used to determine heteroscedasticity by determining if the error terms were correlated across observations in the cross sectional data (Long \& Ervin, 2000). The hypothesis was that;

$\mathrm{H}_{0}$ : The data is not Homoscedastic.

$\mathrm{H}_{1}$ : The data is Homoscedastic.

If the p-value is less than 0.05 , the hypothesis is rejected. Results are presented in Table 5. 
Stratford Peer Reviewed Journals and Book Publishing

Journal of Finance and Accounting

Volume 6||Issue 1||Page 57-70 ||January||2022|

Email: info@stratfordjournals.org ISSN: 2616-4965

Table 5: Heteroscedasticity Results

\section{Breusch-Pagan / Cook-Weisberg test for heteroskedasticity \\ $\mathrm{H}_{0}$ : Constant variance \\ Variables: fitted values of Sustainability}

$\mathrm{H}_{0}: \operatorname{sigma}(\mathrm{i})^{\wedge} 2=\operatorname{sigma}^{\wedge} 2$ for all $\mathrm{i} \operatorname{chi} 2(1)=6.25$

Prob $>$ chi $2=0.081$

Results shown is Table 5 indicate that the p-value is greater than 5\%. Then, the hypothesis was not rejected at a critical p-value of 0.05 since the reported $\mathrm{Chi}^{2}(1)=6.25$ and p-value was $0.081>$ 0.05; thus the data did not suffer from heteroscedasticity.

\subsection{Results of Regression Analysis}

Regression analysis was used to determine the statistical significance of four variables on the business sustainability of supermarkets in Nairobi County, Kenya: technological feasibility, economic feasibility, operational feasibility, and legal feasibility. The results in Table 6 summarize the regression model's performance in describing the study's phenomena.

Table 6: Regression Model

\begin{tabular}{|c|c|c|c|c|c|}
\hline \multicolumn{6}{|c|}{ Rsquared } \\
\hline Model & $\mathbf{R}$ & R Square & $\begin{array}{l}\text { Adjusted R } \\
\text { Square }\end{array}$ & & $\begin{array}{l}\text { Std. Error } \\
\text { of the } \\
\text { Estimate }\end{array}$ \\
\hline 1 & $.877 \mathrm{a}$ & 0.77 & 0.763 & & 0.35527 \\
\hline \multicolumn{6}{|c|}{ ANOVA } \\
\hline & Sum of Squares & df & Mean Square & $\mathbf{F}$ & Sig. \\
\hline Regression & 56.187 & 4 & 14.047 & 111.292 & $.000 \mathrm{~b}$ \\
\hline Residual & 16.787 & 133 & 0.126 & & \\
\hline \multirow[t]{2}{*}{ Total } & 72.973 & 137 & & & \\
\hline & $\begin{array}{l}\text { Unstandardized } \\
\text { B }\end{array}$ & $\begin{array}{l}\text { Coefficients Std. } \\
\text { Error }\end{array}$ & $\begin{array}{l}\text { Standardized } \\
\text { Beta }\end{array}$ & Coefficient & Sig. \\
\hline (Constant) & 1.954 & 0.095 & & 20.669 & 0.000 \\
\hline $\begin{array}{l}\text { Technical } \\
\text { Feasibility }\end{array}$ & 0.172 & 0.045 & 0.271 & 3.791 & 0.000 \\
\hline $\begin{array}{l}\text { Economic } \\
\text { Feasibility }\end{array}$ & 0.094 & 0.047 & 0.153 & 1.99 & 0.049 \\
\hline $\begin{array}{l}\text { Operational } \\
\text { Feasibility }\end{array}$ & 0.134 & 0.045 & 0.225 & 2.986 & 0.003 \\
\hline $\begin{array}{l}\text { Legal } \\
\text { Feasibility }\end{array}$ & 0.211 & 0.041 & 0.337 & 5.163 & 0.000 \\
\hline
\end{tabular}

The variables used in the study: technical feasibility, economic feasibility, operational feasibility, legal feasibility were found to be satisfactory variables in explaining business sustainability of supermarkets. This is supported by coefficient of determination also known as the Rsquare of 0.77. 
This means that technical feasibility, economic feasibility, operational feasibility, legal feasibility explain $77 \%$ of the variations in the dependent variable, which implies there was business sustainability of the supermarkets under study. This results further mean that the model applied to link the relationship of the variables was satisfactory. Additionally, the findings confirm that the regression model is significant, as evidenced by $\mathrm{F}=111.292$, $\mathrm{p}<0.000$ ), because the $\mathrm{p}$-values were less than 0.05. The regression analysis of coefficients was used to determine the statistical significance of the relationship between the independent variables, namely technical feasibility, economic feasibility, operational feasibility, and legal feasibility, and the dependent variable, namely supermarket business sustainability. The constant of 1.954 indicated that if all other factors remained constant, the business sustainability of supermarkets would remain at 1.954 units.

The regression of coefficient results show that technical feasibility and business sustainability of supermarkets was positively and significantly related $(\beta=0.172, p=0.000)$. The results further indicated that economic feasibility and business sustainability of supermarkets was positively and significantly related $(\beta=0.094, p=0.049)$. Moreover, operational feasibility and business sustainability of supermarkets was also positively and significantly related $(\beta=0.134, p=0.003)$. Lastly, results showed that legal feasibility and business sustainability of supermarkets was positively and significantly related $(\beta=0.211, \mathrm{p}=0.000)$.

The regression model was presented as follows.

$\begin{array}{ll}\mathrm{Y}=1.954+0.172 \mathrm{X}_{1}+0.094 \mathrm{X}_{2}+0.134 \mathrm{X}_{3}+0.211 \mathrm{X}_{4} \\ \mathrm{Y}= & \text { Business Sustainability of Supermarkets } \\ \mathrm{X}_{1}= & \text { Technical Feasibility } \\ \mathrm{X}_{2}= & \text { Economic Feasibility } \\ \mathrm{X}_{3}= & \text { Operational Feasibility } \\ \mathrm{X}_{4}= & \text { Legal Feasibility }\end{array}$

The findings are in line with Santos (2019) who conducted a study on the impact of technical feasibility study as a tool for successful business operation in Enugu Urban, Nigeria, and established a positive relationship with successful business operation. The findings are also consistent with Sailewu (2016) who assessed the perception of supermarkets in Nairobi on the use of technical feasibility and established a positive and significant relationship. A positive relationship was also observed by Rubi (2018), whose study examined the influence of technical feasibility orientation on the performance of supermarkets. Maina (2019) study on the impact of technical and market feasibility on performance of Kenyan supermarkets observed technical and market feasibility process influence commerce applications in Kenyan supermarkets to a great extent.

The findings corroborate Nicholas and Chinedum's (2017) study on the influence of feasibility studies on project and business sustainability, which found that doing feasibility studies significantly increases business sustainability. This is because it lets the organization to detect defects, obstacles, and unforeseeable occurrences that could impede the organization's success in 
order to take necessary preventative steps. Additionally, the findings corroborate Makinde's (2013) analysis of the relationship between feasibility study and business plan in Nigeria. Makinde's study established a high correlation between feasibility studies and business performance. As a result, the study recommended that where feasible and essential, feasibility studies be done and the results utilized. Rodney (2017) notes that while determining the viability of a project is crucial for economic success, other variables may be involved, and invariably, luck will play a role. A critical component of any feasibility study is ensuring that one is dealing with accurate facts, reasonable assumptions, and current financial data. Many undertakings fail as a result of faulty assumptions.

Further, Njoka's (2019) study on the market operational elements impacting consumer choice of supermarkets in Nairobi, Kenya, established that strategically positioned stores, extended hours of operation, unique discounts, and high-quality products all contributed to winning customers. The three lowest-ranked components are sufficient sales associates, product delivery to parking lots, and home delivery of bulk goods. Mwangi (2018) also explored the determinants affecting the viability of retail enterprises in Kenya, focusing on a sample of selected Nairobi supermarkets. The findings indicated that the variables generated statistically significant values and may be used to explain the retail business's sustainability in Kenya. Thus, economic and operational factors such as customer loyalty, governance frameworks, and supplier trust influenced the viability of retail enterprises in Kenya, respectively.

The results correspond those of Matagaro (2018), who examined the factors affecting occupational and legal risk in Kenyan grocery chains. Matagaro's studies suggested that legal feasibility has a substantial impact on the viability of businesses. Additionally, the study found that the likelihood of occupational fraud has decreased slightly, which could be attributable to supermarkets implementing internal control mechanisms. However, the vice had not been completely eradicated as a result of lax control systems, employee discontent with their jobs, easy access to organizational resources, and demanding employee lifestyle patterns. Similarly, due to the huge number of thirdparty touch points in the procurement and supply chain, the sector is extremely exposed to bribery and corruption. The findings corroborate those of Manab, Othman, and Kassim (2018), who evaluated the legal feasibility of enterprise management in Malaysia and concluded that integrating legal compliance resulted in the achievement of organizational goals and maximization of shareholder value. This means that adhering to business and operational regulations success fully is a step toward sustainability.

\subsection{Conclusions}

According to the findings of the study, technical feasibility is positively and significantly associated with the business sustainability of supermarkets in Nairobi County. The responses and indicated that the majority of respondents agreed that technical feasibility improved the business sustainability of supermarkets. In supermarkets, technical feasibility is critical in determining whether technical resources meet capacity and whether the technical team is capable of converting ideas into working systems. The study findings also revealed that, economic feasibility is positively and significantly associated with the business sustainability of supermarkets in Nairobi County. The majority of respondents agreed that economic feasibility improved the business sustainability of supermarkets. Economic feasibility served as an independent assessment that increased credibility, assisting decision-makers in determining the positive economic benefits to supermarkets. Additionally, the study found that operational feasibility was positively and strongly connected with supermarket business sustainability in Nairobi County. The majority of 
respondents felt that operational feasibility increased supermarkets' business viability. Thus, operational feasibility is critical in illustrating how the supermarket's plan met the needs for the firm to continue operating. Further, the study revealed that legal feasibility was positively and strongly connected with supermarkets' commercial sustainability in Nairobi County. The majority of respondents thought that legal feasibility helped supermarkets' business viability. Legal feasibility is critical in establishing whether any component of the proposed supermarket operation violates applicable laws.

\subsection{Recommendations}

\section{Policy Recommendations}

The study recommends that supermarkets become familiar with the technological options available on the market and select those that are appropriate for their operations. The technical viability of the supermarkets' enterprises had a considerable impact on their sustainability. As a result, supermarkets must utilize all available ICT solutions in accordance with their specific needs. Given the high cost of purchasing and implementing certain ICT applications, the study recommends that supermarkets acquire technology that is fit for their operations.

The study recommends that supermarket managers place a premium on optimizing key operational procedures in order to achieve efficiency and sustainability. Additionally, the study advises that supermarket operations managers in Nairobi County compare their business operations functions to those of competitors using incremental innovation. They should also consider comparing their supermarkets to those of diverse business segments in order to identify opportunities to improve related processes and procedures. Finally, the study proposes that supermarkets adhere to established norms and regulations in order to avoid costly litigation.

\section{Recommendations for Management}

Furthermore, the study suggests that management of Nairobi's supermarkets enhance their level of internal and external benchmarking for economic benefit assessments. Managers should use the SWOT analysis approach while doing internal and external benchmarking since it enables them to identify the supermarket's strengths, weaknesses, opportunities, and threats, thereby increasing the supermarket's economic efficiency.

\section{Recommendation for Further Studies}

The study examined the feasibility study's impact on the long-term viability of supermarkets in Nairobi County, Kenya. Because the study was confined to feasibility, more study on competitive strategies in supermarkets, which operate in a highly competitive environment, can be conducted. Additionally, because the study was conducted in Nairobi County, future research might be conducted in other counties in Kenya to compare findings. A descriptive research design was used in this study. Future research could include a cross-sectional design to allow for a more precise comparison of the findings. Finally, future studies can be undertaken in a variety of commercial settings other than supermarkets. 


\section{REFERENCES}

Competition Authority of Kenya. (2020). Retrieved from https://www.google.com/search?client=firefox-b-d\&q=competion+authority+of+kenya

Demmler, K. M., Ecker, O., \& Qaim, M. (2018). Supermarket shopping and nutritional outcomes: a panel data analysis for urban Kenya. World Development, 102, 292-303. https://doi.org/10.1016/j.worlddev.2017.07.018

Gitau, R. (2018). Effect of internal control practices on financial performance of supermarket chains in Nairobi central business district. The Strategic Journal of Business \& Change Management, 6(3), 343-355.

Kanyora, B. (2019). Challenges of strategy implementation at Tusky's supermarket incorporated in Kenya. Nairobi: University of Nairobi.

Maina, J. N. (2016). The impact of technical and market feasibility on performance of Kenyan supermarkets. United States International University - Africa, Nairobi, Kenya.

Makinde, H. O. (2013). The relationship between feasibility study and business plan in Nigeria. International Journal of Advanced Business and Management Research (IJABMR), 1(1).

Manab, N. A., Othman, S. N., \& Kassim, I. (2018). Legal feasibility management best practices in Malaysia. The critical success factors. OIDA International Journal of Sustainable Development, 4(03), 87-96.

Marwa, P., Mithamo, M. K., Letting, D., \& Nicholas, K. (2014). An analysis of challenges facing major supermarkets that emanate from the changing environment: A Case of Kenyan large cities. Journal of Business Management and Economics, 3(4).

Maseko, C. M. (2017). Identification of risk factors affecting construction of projects: The case of emerging economy. Risk Governance and Control: Financial Markets \& Institutions, 7(42), 246-259. http://doi.org/10.22495/rgc7i4c2art7. https://doi.org/10.22495/rgc7i4c2art7

Matagaro, D. K. (2018). Factors influencing occupational and legal risk in supermarket chains in Kenya. Strathmore University, Nairobi, Kenya.

Mithamo, M. K. (2017). Strategic responses of major supermarkets to competition in Kenya. Journal of Business Management and Economics, 3(4).

Muchiri, M. K. (2019). Effect of in-store promotion on consumer purchase behaviour in multinational supermarkets in Nairobi City County. Journal of Business and Retail Management Research, 13(3).

Mwangi, F. W. (2018). Factors affecting sustainability of retail businesses in Kenya: A case of selected supermarkets in Nairobi's Central Business District. Africa Nazarene University, Kenya.

Ndigwa, D. M., \& Moronge, M. (2019). Effect of inventory control strategies on performance of retail chains in Kenya. A case of Naivas supermarket. The Strategic Journal of Business \& Change Management, 6(3), 343-355. 
Nicholas, A. I., \& Chinedum, A. H. (2017). The role of feasibility studies on project and organizational performance. International Journal of Research in Social Sciences, 7(5), 155-170.

Njoka, I. K. (2019). Market operational factors influencing consumer choice of supermarkets in Nairobi, Kenya Kenyatta University, Nairobi, Kenya.

Nzomo, V. (2017). Treatment of buyer power in competition law: Case of supermarket retail sector in Kenya. The Law Society of Kenya Journal, 13(1).

Organisation for Economic Co-operation and Development, \& Statistical Office of the European Communities. (2019). Oslo Manual 2019: Guidelines for collecting, reporting and using data on innovation. London: OECD Publishing.

Ouma, D. (2018). A proposed feasibility model for supermarket branch network expansion in Kenya. Jomo Kenyatta University of Agriculture and Technology, Kenya.

Rahimi, R. (2018). Feasibility study of application and implementation of customer relationship management (CRM) in hotel industry. Journal of Accounting, 2(1), 54-68.

Rahman, M. A., \& Mazlan, A. R. (2014). Determinants of operational efficiency of microfinance institutions in Bangladesh. Asian Social Science, 10(22), 322. https://doi.org/10.5539/ass.v10n22p322

Retail Traders Association of Kenya (2020). Retrieved from https://www.google.com/search?client=firefoxbd\&q=Retail+Traders+Association+of+Kenya

Reynolds, P. D., \& Curtin, R. T. (2018). Business creation in the United States: Panel study of entrepreneurial dynamics II initial assessment (Vol. 16). London: Sage Publications. https://doi.org/10.4337/9781788118354

Rodney, O. (2017). Operational feasibility studies for sustainability made simple. Martin Books Pty Ltd ACN, 112(719), 052.

Rubi, V. M. (2018). Influence of competitive strategies on the performance of supermarkets in Nairobi central business district. United States International University - Africa, Nairobi, Kenya.

Sailewu, E. M. (2016). The perception of supermarkets in Nairobi on the use of technical feasibility. University of Nairobi, Nairobi, Kenya.

Santos (2019). Impact of technical feasibility study (report) as a tool for successful business operation in Enugu Urban, Nigeria. International Journal of Economic Policy in Emerging Economies, 10, 226-39.

Wilburn, K. M., \& Wilburn, H. R. (2018). The impact of technology feasibility on business and society. Global Journal of Business Research, 12(1), 23-39. 